\title{
Research Letter \\ Ultrasoft and High Magnetic Moment CoFe Films Directly Electrodeposited from a B-Reducer Contained Solution
}

\author{
Baoyu Zong, Guchang Han, Jinjun Qiu, Zaibing Guo, Li Wang, Wee-Kay Yeo, and Bo Liu \\ Data Storage Institute, A-Star, 5 Engineering Drive 1, National University of Singapore (NUS), Singapore 117608
}

Correspondence should be addressed to Baoyu Zong, zong_baoyu@dsi.a-star.edu.sg

Received 13 March 2008; Accepted 20 May 2008

Recommended by Eli Ruckenstein

A methodology to fabricate ultrasoft CoFe nano-/microfilms directly via electrodeposition from a semineutral iron sulfate solution is demonstrated. Using boron-reducer as the additive, the CoFe films become very soft with high magnetic moment. Typically, the film coercivity in the easy and hard axes is 6.5 and 2.5 Oersted, respectively, with a saturation polarization up to an average of 2.45 Tesla. Despite the softness, these shining and smooth films still display a high-anisotropic field of $\sim 45$ Oersted with permeability up to $10^{4}$. This kind of films can potentially be used in current and future magnetic recording systems as well as microelectronic and biotechnological devices.

Copyright (c) 2008 Baoyu Zong et al. This is an open access article distributed under the Creative Commons Attribution License, which permits unrestricted use, distribution, and reproduction in any medium, provided the original work is properly cited.

\section{INTRODUCTION}

The ever expanding demand of the world market leads to magnetic recording data storage devices advancing toward much smaller exterior dimension and higher capacity $[1,2]$. In order to achieve very high capacity and fast recording data storage in a miniature device, an ultrasoft and high magnetic moment material is required for producing highsaturation flux density $\left(B_{s}\right)$, so that the necessary flux density can be preserved on reducing device dimensions, while simultaneously achieving a low coercivity $\left(H_{c}\right)$ to match the hard magnetic media with high $H_{c}$, track density, and linear density [3]. Soft magnetic films with high moment are also widely used in modern electromagnetic devices, such as high-frequency field-amplifying components, versatile communication tools, and magnetic shielding materials in tuners [4]. Although numerous soft or high- $B_{s}$ magnetic films have been achieved nowadays via sputtering, evaporation, and casting, most of them cannot be applied to device fabrication due to the following reasons: low-deposition rate (usually $<8 \AA / S$ ) and high-internal stress films from sputtering [5], overly thick films (commonly $>1 \mathrm{~mm}$ ) from casting, and coarse-grained films from evaporation [6]. In addition, most of the reported materials have limited $B_{s}$ of $\leq 2.1 T$ (e.g., NiFe, FeCoNi films) [3]. Despite CoFe alloy possessing the highest $B_{s}$ of about $2.45 T$ theoretically, the
CoFe nano/microfilms prepared always encounter two vital issues for application: poor magnetic properties [such as poor anisotropy, high value of $H_{c}$ (always $>4$ Oerted $(O e)$ ) ] and poor mechanical properties (such as rough surface, and cracking film) [7]. Electrodeposition is a fast and simple method to achieve various thicknesses of soft Febased materials with lower stress $[8,9]$. However, preventing $\mathrm{Fe}^{2+}$ from oxidization into $\mathrm{Fe}^{3+}$ (which decreases $B_{s}$ ), and minimizing the $H_{c}$ and roughness of the metal films are challenges in electrodeposition $[3,7]$. So far, only the softest magnetic CoFe film, which possesses an easy axis $H_{c}\left(H_{c e}\right)$ and hard axis $H_{c}\left(H_{c h}\right)$ of 15 and $4.8 O e$, respectively, has been reported [7].

Herein, we demonstrate a novel approach to the fabrication of ultrasoft magnetic CoFe films via electrodeposition from a sulfate salt-based solution containing dimethylamine borane $\left[\left(\mathrm{CH}_{3}\right)_{2} \mathrm{NHBH}_{3}\right]$ (B-reducer, Bayer AG, Germany). In comparison with commonly used strong acidic solutions (corroding devices) which contain $S$-additives (saccharin, $\mathrm{Na}$ Lauryl sulfate), the solution containing B-reducer is a semineutral medium with larger process latitude. For instance, the $\mathrm{pH}$ range $(3.5-5.1)$ is much wider than that of the common plating solutions containing $S$-additives $(\mathrm{pH}=2.3-2.5$ or $2.5-3.0)[7,9]$. Furthermore, the plating solution does not require a salt bridge to protect $\mathrm{Fe}^{2+}$ from oxidization. The thickness of the prepared films measured 
TABLE 1: Property comparison of CoFe films (without annealing).

\begin{tabular}{lcccc}
\hline Property & No additive & B-reducer $(1.5 \mathrm{~g} / \mathrm{L})$ & B-reducer $(3 \mathrm{~g} / \mathrm{L})$ & $S$-additive \\
\hline$H_{c e}(O e)$ & 63 & 6.6 & 6.5 & 13 \\
$H_{c h}(O e)$ & 53 & 5.8 & 2.5 & 4.8 \\
$H_{k}(O e)$ & 78 & 26 & 45 & 20.2 \\
$\mu_{m}$ & $7.8 \times 10^{1}$ & $4.5 \times 10^{4}$ & $5.8 \times 10^{4}$ & - \\
$B_{s}(T)$ & 1.42 & 2.31 & 2.45 & 2.45 \\
\hline
\end{tabular}

through atomic force microscopy (AFM) ranges from tens of nanometers to micrometers. The magnetic characterizations performed by using vibrating sample magnetometer (VSM) and superconducting quantum interference device (SQUID) show that the films are very soft magnets with good anisotropy and high magnetic moment properties.

\section{METHOD AND RESULTS}

The CoFe films were electrodeposited on $\mathrm{Si}(100)$ wafers. A seed layer, for example, $\mathrm{Au}, \mathrm{Cu}$, or $\mathrm{CoFe}$, with thickness of $20-30 \mathrm{~nm}$ was sputtered onto each wafer surface as an electrical conducting layer for the electrodeposition. The $\mathrm{Fe}_{\mathrm{x}} \mathrm{Co}_{100-x}(x=55-68)$ films were fabricated at the temperature of $40 \pm 2{ }^{\circ} \mathrm{C}$ from a solution of $0.07 \mathrm{~mol} / \mathrm{L}$ $\mathrm{CoSO}_{4} \cdot 7 \mathrm{H}_{2} \mathrm{O}, 0.10 \mathrm{~mol} / \mathrm{L} \mathrm{FeSO}_{4} \cdot 7 \mathrm{H}_{2} \mathrm{O}, 0.5 \mathrm{~mol} / \mathrm{L} \mathrm{NH}_{4} \mathrm{Cl}$, $0.5 \mathrm{~mol} / \mathrm{L} \mathrm{H}_{3} \mathrm{BO}_{3}$, and $2.8-3.2 \mathrm{~g} / \mathrm{L} \mathrm{B}$-reducer additive. The electroplating system used was a Paddle cell with pulse DC power. During the electrodeposition of CoFe film, a magnetic field of $280 \mathrm{Oe}$ was applied parallel to the substrate surface. The atomic ratio of Co to Fe in the electrodeposited films was determined by energy dispersive X-ray (EDX, JSM-6340F, JEOL Asia). While measuring $H_{c}$ with the VSM possessing Helmoltz coils, high resolution of $0.01 \mathrm{Oe}$ was obtained through the field control mode. The maximum relative permeability $\left(\mu_{m}\right)$ was calculated from easy axis $M-H$ loops according to the formula $\mu_{m}=B(T) / H(T) \approx 4 \pi$ magnetic moment $(M, \mathrm{emu}) /[$ magnetic field $(H, \mathrm{Oe}) \times$ film volume $\left.\left(\mathrm{cm}^{3}\right)\right]$, where $(M, H)$ refers to the turning point in the lower branch of the easy axis $M-H$ loop. It is noted that the effect of film sample shape (normally, $1.20 \mathrm{~cm} \times 1.20 \mathrm{~cm}$ $\times \sim 0.6 \mu \mathrm{m}$ ) can be neglected due to the length and width being much larger than the thickness $[10,11]$. The $B_{s}$ values were calculated from the formula $B_{s}(T)=\mu_{0} M_{s}=4 \pi \times 10^{4} M$ (emu)/film volume $\left(\mathrm{cm}^{3}\right)$, where $M$ refers to the saturation moment in the $M-H$ loops. The $B_{s}$ result is the average value obtained from a series of CoFe films having different thickness $(80 \mathrm{~nm}-2.5 \mu \mathrm{m})$. The dimension of the films was measured on ADM-60 Micro-Dicer. The total error of $B_{s}$ measurement is $0.01 T$.

Table 1 shows that the B-reducer dramatically induces the decrease of $H_{c}$ and the increase of $B_{s}$ with its addition increasing from 0 to $100 \mathrm{~mL} / \mathrm{L}$. It is due to the fact that despite the absence of salt bridge (leading to a lower efficiency of plating current) to prevent $\mathrm{Fe}^{2+}$ from oxidization in the solution, the B-reducer can protect the as-synthesized CoFe film effectively from oxidization since B-reducer, acting

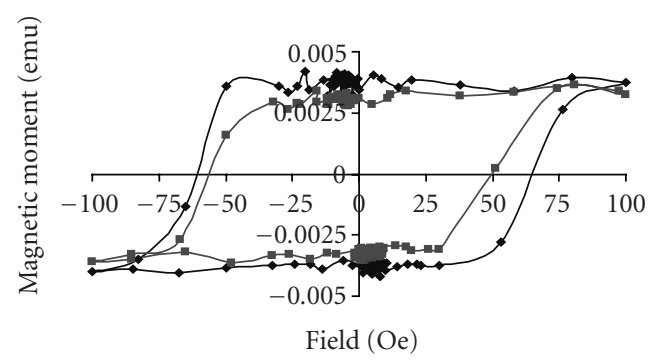

(a)

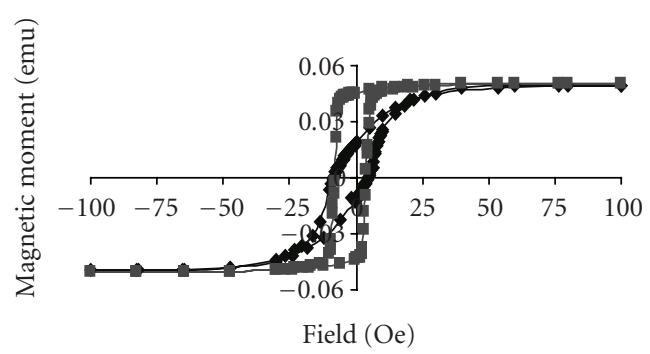

(b)

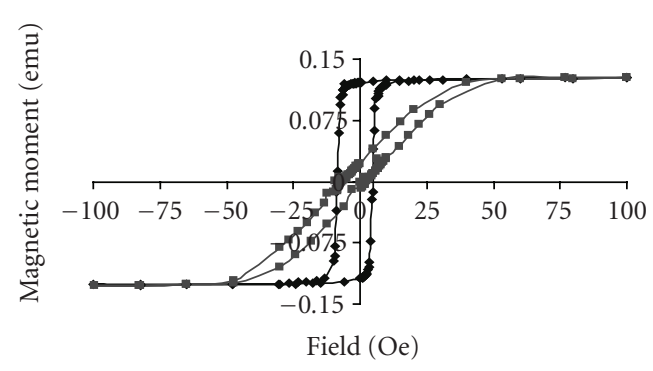

(c)

Figure 1: The $M-H$ loops of the $\mathrm{Co}_{40} \mathrm{Fe}_{60}$ films electrodeposited (at a current density of $\sim 6.0 \mathrm{~mA} / \mathrm{cm}^{2}$ ) from the solutions which contain $B$-reducer of (a) 0.0 , (b) 1.5 , and (c) $3.0 \mathrm{~g} / \mathrm{L}$, respectively.

as a reductant molecule, can reduce $\mathrm{Fe}^{3+}$ (produced during plating) back into $\mathrm{Fe}^{2+}$ :

$$
\begin{aligned}
& \mathrm{Fe}^{2+}-\mathrm{e} \stackrel{\mathrm{O}_{2} \text { or at anode }}{\longrightarrow} \mathrm{Fe}^{3+} \text { (by-reaction) } \\
& \mathrm{Fe}^{3+}+\mathrm{e} \stackrel{\text { B-reducer }}{\longrightarrow} \mathrm{Fe}^{2+} .
\end{aligned}
$$

Despite the addition, the B-reducer did not lead to too much boron doping into the CoFe film. Hence, there is a very low content of oxygen and boron present in the deposited CoFe films, in which the low oxygen content 


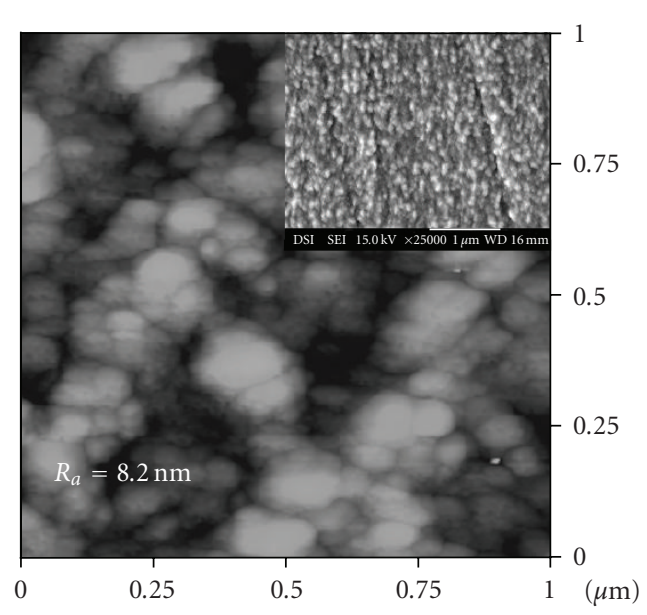

(a)

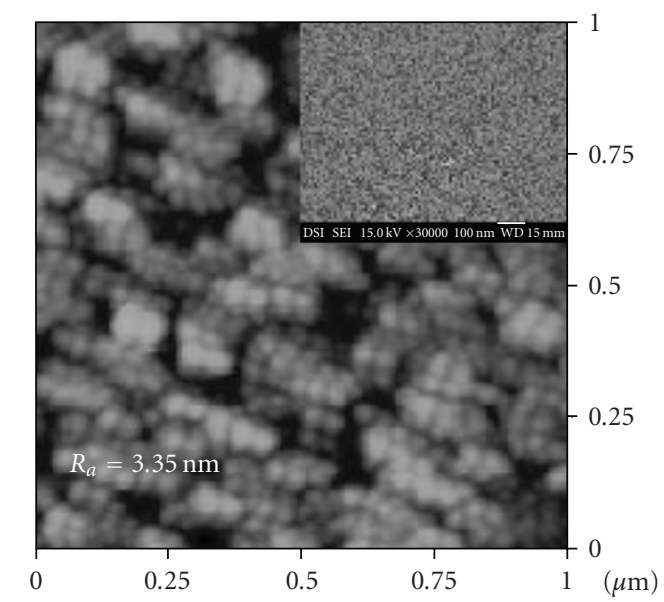

(b)

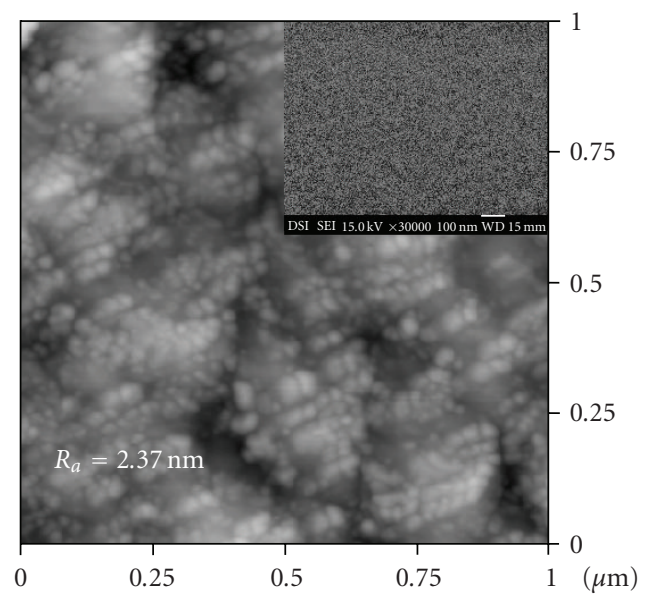

(c)

Figure 2: The AFM and FESEM (inset) images of the $\mathrm{Co}_{40} \mathrm{Fe}_{60}$ films electrodeposited (at a current density of $\sim 6 \mathrm{~mA} / \mathrm{cm}^{2}$ ) from the solutions which contain $B$-reducer of (a) 0 , (b) 1.5 , and (c) $3.0 \mathrm{~g} / \mathrm{L}$, respectively. The scale bar in the inset (a)-(c) is $1 \mu \mathrm{m}, 100$, and $100 \mathrm{~nm}$, respectively. cannot be detected by EDX, while the boron content is less than $0.8 \%$ after XPS analyzing. For the $\mathrm{Co}_{40} \mathrm{Fe}_{60}$ film deposited from a current density of $6.0 \mathrm{~mA} / \mathrm{cm}^{2}$, with the concentration of B-reducer increasing from 0.0 to $3.0 \mathrm{~g} / \mathrm{L}$ in the electroplating solution, the $H_{c e}$ and $H_{c h}$ values decrease from 63 and 53 to 6.5 and $2.5 \mathrm{Oe}$, respectively, while $B_{s}$ increases from 1.4 to $2.45 T$ in average. On the other hand, the permeability $\left(\mu_{m}\right)$ of CoFe film also increases from the order of $10^{1}$ to $10^{4}$ after the addition of B-reducer. Thus, the film becomes very soft due to the effect of B-reducer. Figure 1 shows the magnetic moment-applied field curves (M-H loops) of the CoFe films from the solutions containing different concentrations of B-reducer. It appears that the loops along the easy and hard axes change from being similar [such as in Figure 1(a)] to distinctly different [shown in Figure 1(c)]. Hence, the ultrasoft and high magnetic moment of $\mathrm{Co}_{40} \mathrm{Fe}_{60}$ film possess a much larger anisotropy compared to the softest CoFe films reported to date [7]. Further investigations revealed that although similar effects of B-reducer had also been observed for other components of CoFe films by varying the plating current density, only the films with formulas from $\mathrm{CO}_{35} \mathrm{Fe}_{65}$ to $\mathrm{Co}_{43} \mathrm{Fe}_{57}$ could achieve a high $B_{s}$ of $\geq 2.4 T$, and such films were electrodeposited at a current density ranging between 4.8 and $7.2 \mathrm{~mA} / \mathrm{cm}^{2}$.

More measurements were carried out to identify the mechanism for the effect of B-reducer on the properties of CoFe films. In Figure 2, the AFM and FESEM images show the surface variations of the deposited $\mathrm{Co}_{40} \mathrm{Fe}_{60}$ films with the increase of B-reducer concentration from 0 to 1.5 , then to $3.0 \mathrm{~g} / \mathrm{L}$. The sizes of CoFe nanoparticles become much smaller (roughly from 80 to $10-30 \mathrm{~nm}$ ) with the increase of B-reducer concentration in the electroplating solution. Thus, for the films, $H_{c}$ drops and $\mu_{m}$ increases drastically since the average magnetocrystalline anisotropy and the exchange coupling range become lower and wider, respectively, with the smaller ferromagnetic nanoparticles $[10,11]$. In addition, X-ray diffraction (XRD) analysis (recorded from a powder sample) in Figure 3 shows that the added $\mathrm{B}$-reducer eliminates the foreign $\mathrm{Fe}_{2} \mathrm{O}_{3}$-phase (viz. protects $\mathrm{Fe}^{2+}$ from oxidization), which leads to a texturestructural change from $\mathrm{CoFe}(110)$ and $\mathrm{Fe}_{2} \mathrm{O}_{3}(209)$ polycrystalline to $\mathrm{CoFe}(110)$ single-crystalline for the $\mathrm{Co}_{40} \mathrm{Fe}_{60}$ films. As a result, the film possesses very low $H_{c}$ [11] and high theoretical $B_{s}$ value $(\sim 2.45 T)$ [7]. Further investigation results revealed that too much of B-reducer $(>10 \mathrm{~g} / \mathrm{L})$ led to an unstable plating solution and a high content of boron doping $(>2 \%)$ in the CoFe films. The films possess an amorphous texture, a decreased $B_{s}$, and poor anisotropy.

Apart from having excellent magnetic properties, our characterizations shown in Table 2 indicate that the CoFe films also displayed good mechanical and other properties, such as very low magnetostriction $\left(\lambda_{s}\right)$ and surface roughness $\left(R_{a}\right.$, also depicted in Figure 1), and absence of microcracking defects, which is a critical problem faced by current CoFe electrodeposition [7, 12]. These properties also contribute to low $H_{c}$ of the films [10]. 
TABLE 2: Properties of soft $\mathrm{Co}_{40} \mathrm{Fe}_{60}$ films.

\begin{tabular}{lcccccc}
\hline Film & $H_{c e}(\mathrm{Oe})$ & $H_{c h}(\mathrm{Oe})$ & $B_{s}(T)$ & $\lambda_{s}\left(\times 10^{-6}\right)$ & Surface & $R_{a}(\mathrm{~nm})$ \\
\hline Before anneal & 6.5 & 2.5 & 2.45 & 9.2 & Shining & 2.4 \\
After anneal & 5.6 & 1.8 & 2.43 & 3.4 & Shining & 2.2 \\
\hline
\end{tabular}

Note: the annealing was conducted at $200^{\circ} \mathrm{C}$ for 4 hours.

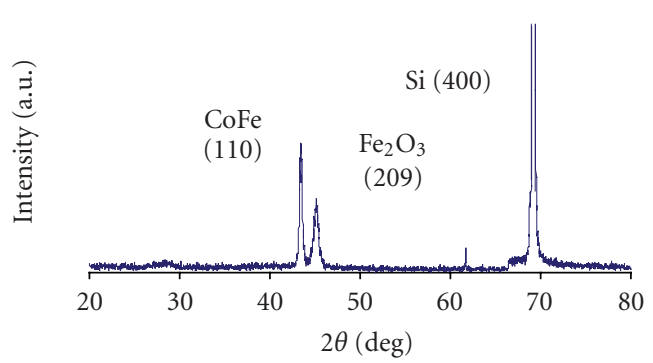

(a)

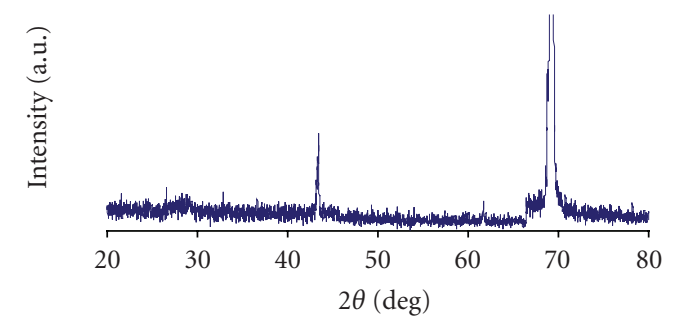

(b)

FIgURE 3: The $2 \theta$ XRD results of $\sim 0.6 \mu \mathrm{m} \mathrm{Co}_{40} \mathrm{Fe}_{60}$ films on $\mathrm{Si}(100)$ wafer. (a) and (b) stand for without adding and adding B-reducer, respectively.

\section{CONCLUSION}

The two challenging issues (poor magnetic and mechanical properties), encountered in the preparation of high- $B_{s}$ magnetic CoFe films [7], can simply be solved by using boron reducer in electrodeposition. The boron reducer can greatly improve the softness, magnetic moment, mechanical, and other properties of the CoFe films. Thus, the as-prepared films have potential applications in ultrahigh density and frequency magnetic recording system, biotechnological, and microelectronic devices $[2,4]$.

\section{ACKNOWLEDGMENT}

The authors would like to thank Mr. J. F. Chong for XRD measurement.

\section{REFERENCES}

[1] S. R. Brankovic, X. Yang, T. J. Klemmer, and M. Seigler, "Pulse electrodeposition of $2.4 \mathrm{~T} \mathrm{Co}_{37} \mathrm{Fe}_{63}$ alloys at nanoscale for magnetic recording application," IEEE Transactions on Magnetics, vol. 42, no. 2, pp. 132-139, 2006.

[2] P. C. Andricacos and N. Robertson, "Future directions in electroplated materials for thin-film recording heads," IBM
Journal of Research and Development, vol. 42, no. 5, pp. 671680, 1998.

[3] T. Osaka, M. Takai, K. Hayashi, K. Ohashi, M. Saito, and K. Yamada, "A soft magnetic CoNiFe film with high saturation magnetic flux density and low coercivity," Nature, vol. 392, no. 6678, pp. 796-798, 1998.

[4] Ultrasoft magnetic films for high-frequency inductors (GWN. 4561), http://www.stw.nl/Projecten/G/gwn/gwn4561.htm.

[5] S. X. Wang, N. X. Sun, M. Yamaguchi, and S. Yabukami, "Sandwich films: properties of a new soft magnetic material," Nature, vol. 407, no. 6801, pp. 150-151, 2000.

[6] W. Yu, J. A. Bain, Y. Peng, and D. E. Laughlin, "Magnetization reduction due to oxygen contamination of bias sputtered $\mathrm{Fe}_{35} \mathrm{Co}_{65}$ thin films," IEEE Transactions on Magnetics, vol. 38, no. 5, pp. 3030-3032, 2002.

[7] E. I. Cooper, C. Bonhôte, J. Heidmann, et al., "Recent developments in high-moment electroplated materials for recording heads," IBM Journal of Research and Development, vol. 49, no. 1, pp. 103-126, 2005.

[8] B. Zong, Y. Wu, G. Han, et al., "Synthesis of iron oxide nanostructures by annealing electrodeposited Fe-based films," Chemistry of Materials, vol. 17, no. 6, pp. 1515-1520, 2005.

[9] M. Kawasaki and Y. Kanada, "Soft magnetic film having high saturation magnetic flux density, thin-film magnetic head using the same, and manufacturing method of the same," US patent no. 6765757, August 2002.

[10] G. Herzer, "Soft magnetic nanocrystalline materials," Scripta Metallurgica et Materialia, vol. 33, no. 10-11, pp. 1741-1756, 1995.

[11] Q. Zeng, I. Baker, V. McCreary, and Z. Yan, "Soft ferromagnetism in nanostructured mechanical alloying FeCo-based powders," Journal of Magnetism and Magnetic Materials, vol. 318, no. 1-2, pp. 28-38, 2007.

[12] F. Lallemand, L. Ricq, E. Deschaseaux, L. De Vettor, and P. Berçot, "Electrodeposition of cobalt-iron alloys in pulsed current from electrolytes containing organic additives," Surface \& Coatings Technology, vol. 197, no. 1, pp. 10-17, 2005. 


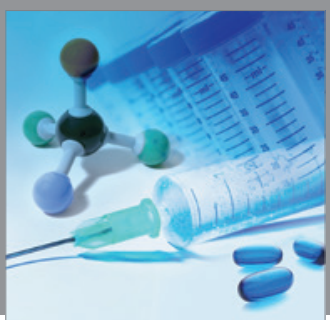

International Journal of

Medicinal Chemistry

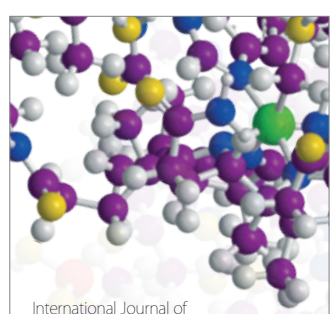

Carbohydrate Chemistry

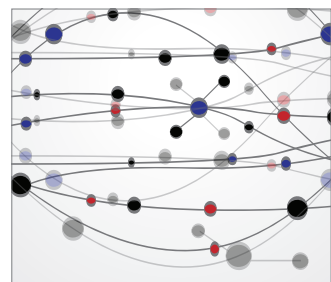

The Scientific World Journal
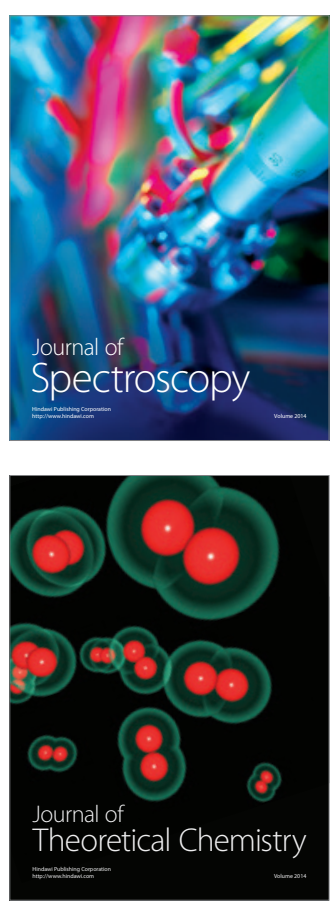
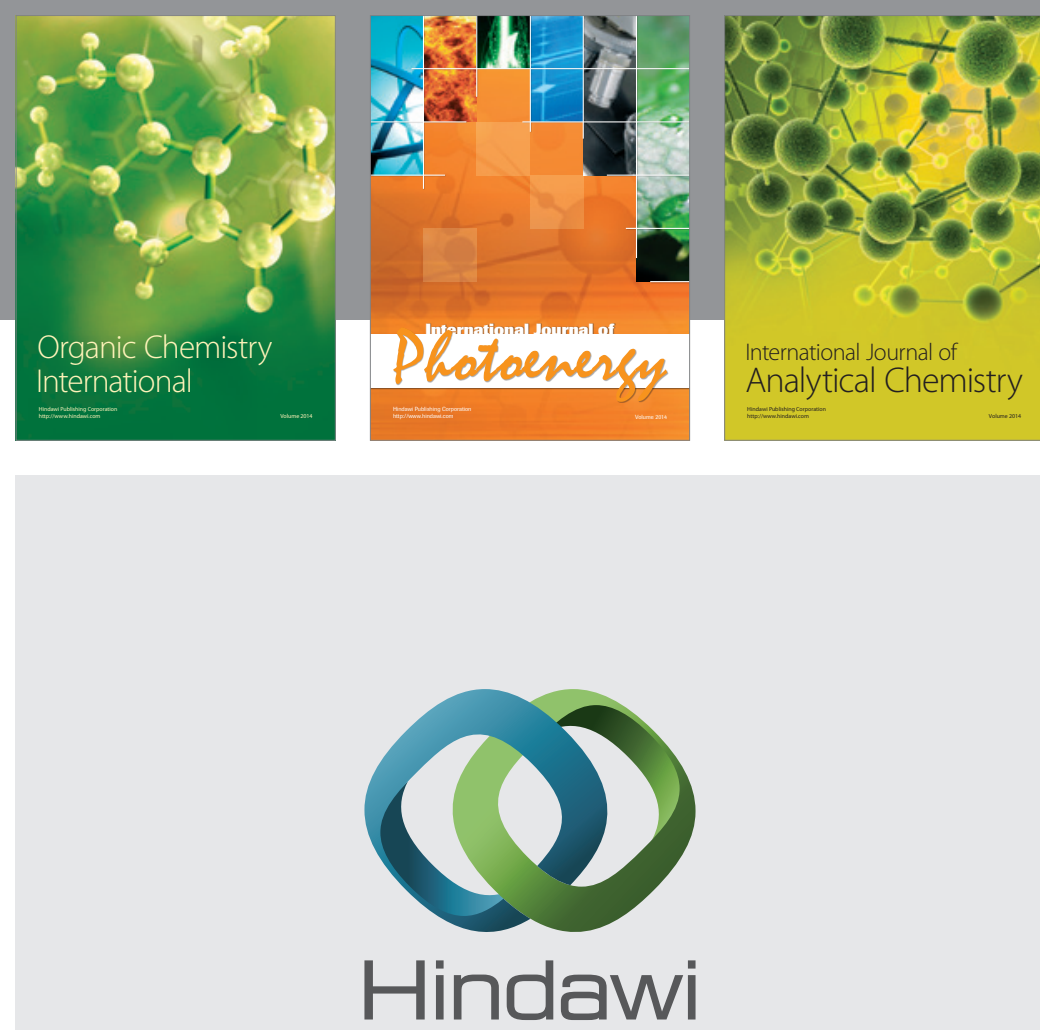

Submit your manuscripts at

http://www.hindawi.com
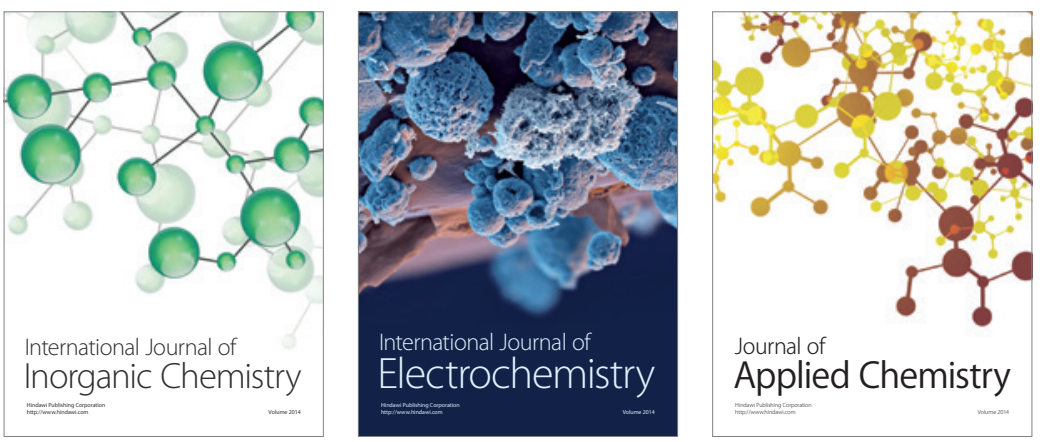

Journal of

Applied Chemistry
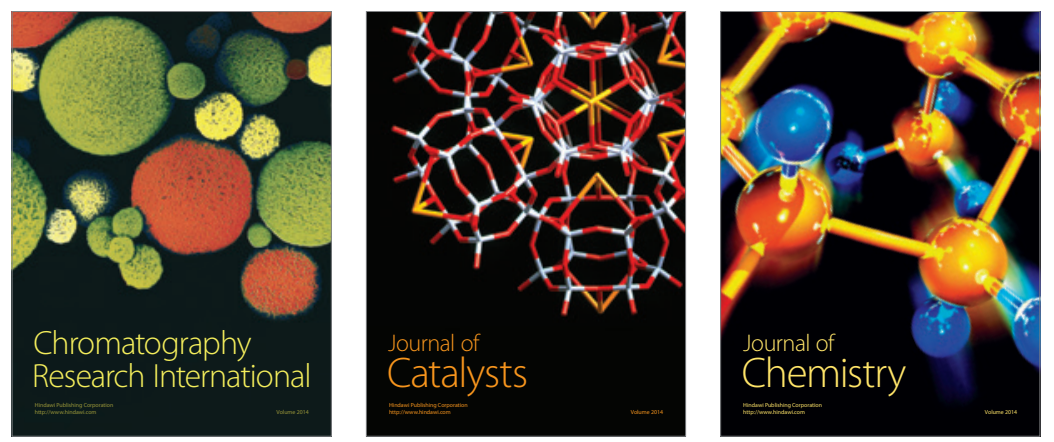
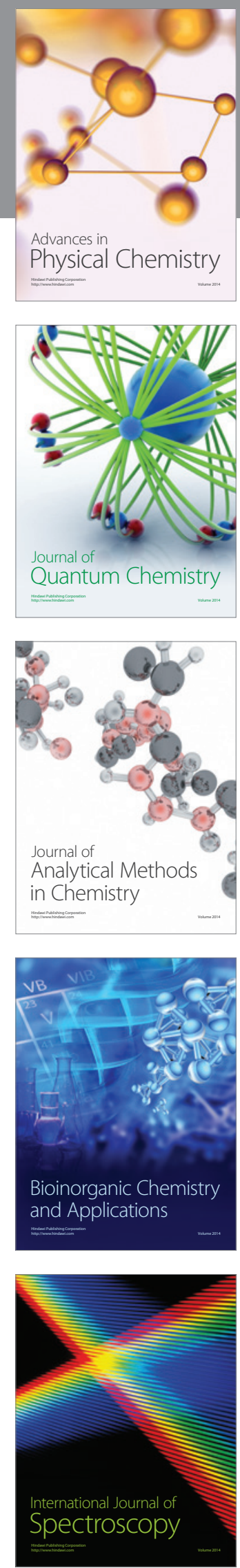